\title{
En hetero på laget
}

Af Heidi Eng

Hva skjer nair det kommer et homoidrettslag inn i mainstreamidretten? Kan idvettslaget 'fuck up the mainstream' og samtidig forbli et prestasjonsorientert haindballag? $O g$ bva skjer med homoidrettslaget selv, nair de fàr en hetero på laget? Det kan en queer-inspirert analyse av spenningsfeltet $i$ og rundt et norsk bomoidrettslag, fortelle noe om.
Queer activists saw Outrage as distinctly anti-assimilationist compared to the parliamentary reform group, Stonewall which has been established as a response to Clause 28 in 1989 ... Ontrage activists are not interested in seeking acceptance within an unchanged social system, but are setting out to "fuck up the mainstream" as visibly as possible. (Smyth 1992: 19-20)

viser til en periode i den internasjonale homopolitikkens historie, hvor queerbevegelsen (her 'Outrage') ble etablert i protest mot det som ble oppfattet som en assimilasjon av homoseksualitet inn i 'normaliteten'. ${ }^{1}$ I dag er assimilasjonspolitikken fortsatt illustrert gjennom for eksempel kampen for likestilt rett til ekteskapet som en statlig normativ samlivsregulering. 'Outrage' proklamerte en annen politisk strategi som innebar å kjempe for retten til annerledeshet gjennom en 'in your face' taktikk; en provokativ synlighet med mål å plassere 
seg i det 'normale sentrum' for å endre/utvide forståelsen av normalitet innenfra i stedet for å etablere alternative gettoer som "queer zones and other worlds estranged from heterosexual culture" (Berlant \& Warner 2002: 187). Det siste ('queer zones') kan også være et utrykk for antiassimilasjonspolitikk, men uten potensial til, eller mål om, å påvirke mainstreamkulturen (Eng 2006: 20-21).

I denne artikkelen vil jeg drøfte om disse konfliktlinjene er en aktuell problemstilling i konteksten norsk idrett. Mer konkret vil jeg studere 'homoidrettslaget' Raballder Håndball klubb som deltar i en mainstream idrettskonkurranse, nærmere bestemt 3. divisjon herrehåndball i Norge. Egne 'homoidrettslag' har eksistert på både kvinneog herresiden i ulike idrettsdisipliner siden tidlig 90-tall i Norge. Men Raballder skiller seg ut fra andre homoidrettslag fordi de konkurrerer på relativt høyt nivå som et 'homolag' i 'vanlig' seriespill. ${ }^{2}$ Flere studier har vært opptatt av spørsmål vedrørende endringspotensial knyttet til homoseksualitet og/eller 'homoidrett' i en mainstream idrettskontekst (Price \& Parker 2003, Elling \& Claringbould 2005, Anderson 2005, Larsson 2005, Caudwell 2006, Bridel \& Rail 2007, Eng 2008). Det er derfor interessant å se på Raballder som 'homoidrettslag' fordi de er i en mulig posisjon til nettopp å effektuere det Cherry Smyth i sitatet over kaller "to fuck up the mainstream" i motsetning til egne 'homoidrettsturneringer' som kan bli forstått som en 'queer zone' atskilt og utdefinert som annerledes fra 'normal/vanlig idrett' (OL versus Gay Games, World Outgames etc. ${ }^{3}$ ). Fotografiet av Raballder over illustrerer også ulike former for synlighet, med den forreste rekken av utøvere som viser tenner og klør og lange lekre ben, i motsats til den bakerste rekken med 'macho' idrettsmenn tilsynelatende assimilert inn i det som er påpekt som en hegemonisk heteromaskulinitet i det sterke konkurranspektet i idretten (Messner \& Sabo 1994).
Formålsparagrafen til Raballder Håndball Klubb viser også at de ønsker å være synlig i idrettskonteksten sin som et 'homoidrettslag', og bidra til å skape endring i sitt idrettsmiljø både nasjonalt og internasjonalt.

Klubbens formål er å være et sportslig og sosialt tilbud som først og fremst skal rettes mot homofile og lesbiske som ønsker å spille håndball. Dog skal det ikke settes hindringer for andre som ønsker medlemskap, såfremt vedkommende er informert om og innforstått med klubbens statutter. Raballder Håndball Klubb skal stå aktivt frem og bidra positivt til åpenhet omkring homofili og idrett. [...]

(Raballder 2009)

Raballder fremstår her som politiske aktører fordi de i tillegg til å være et tilbud for homofile/lesbiske, også har et politisk ønske om være aktive i en sak de løfter frem; åpenhet omkring homofili og idrett. Jeg synes at formuleringene her, samt promoteringen av laget på bildet, åpner opp for å se flere mulige politiske strategier i virksomhet, noe som gjør dette idrettslaget interessant som et felt for analyse av bruken av virkemidler i et politisk prosjekt.

Mitt første møte med Raballder var som tilskuer på en av kampene deres. Den lille idrettshallen var fylt til trengselen av folk, noe som er uvanlig på en 3 div. håndballkamp i Norge. Folk virket nysgjerrige på å se 'homoene' spille håndball mot hjemmelaget deres. Raballder trakk opp mot 200300 tilskuere til kampene sine $\mathrm{i}$ haller hvor arrangørene ellers var vant til at det kanskje kom noen titalls familiemedlemmer. Jeg satt på tribunen og ble svært nysgjerrig. Våren 2006 tok jeg derfor kontakt med håndballaget og startet opp et feltarbeid som varte hele konkurransesesongen 2006/2007. Jeg fulgte Raballder Håndballklubb både på trening og kamper. ${ }^{4}$ Jeg var interessert $i$ hva som skjer når et homoidrettslag som konkurrerer i 'vanlig' seriespill interagerer med hverandre, med 
motstanderlaget og med alle de andre aktørene som deltar i avviklingen av en håndballserie. I kraft av å ha merkelappen 'homoidrettslag' kan vi si at Raballder Håndballklubb iscenesetter seg som et idrettslag på potensielt mange ulike måter. Jeg ønsker i denne artikkelen å studere nærmere hvilke elementer som kan være aktive i synligjøringen av 'homoidrettslaget'. I fokus for denne artikkelen står derfor spørsmålet om seksualpolitiske strategier og posisjoner i et sosialt og kulturelt nedslagsfelt som vanligvis ikke tildeles mye oppmerksomhet i en nordisk akademisk kontekst (Eng 2006b). Jeg vil belyse dette ved å bruke og drøfte begreper som hetero- og homonormativitet, queer/skeiv og queering/ tilskeivings inspirert av queer teori slik det er blitt utviklet av bl.a. Michael Warner (1999), Lauren Berlant (2002), Don Kulick (1996, 2005), Tiina Rosenberg (2002) og Sasha Roseneil $(2000,2003)$.

\section{"FUCK UP THE MAINSTREAM"?}

Etter at jeg hadde vært i feltet i halvannen måned dukket det opp en ny og for alle helt ukjent håndballspiller på Raballders trening. Etter endt trening får han (Daniel) og flere andre kjøre med Mons hjem, og gutta tøyser ('driller') med Daniel. "Hvem syns du er den kjekkeste Daniel? Liker du Arnfinn eller? Hvem likte du best?" Daniel ler og smiler hele tiden, men sier ingenting. Det er en god stemning i bilen. "Jeg trodde det var sånn litt guttegreie - litt at de bare tøysa ('drille') med meg sånn som gutta gjør når vi er en gjeng. Så jeg flirte bare.. hø, hø - og bare jatta med. Jeg forsto jo ikke noe. At det bare var dårlig spøk at de spurte om jeg syns han var kjekk og sånn". Etter hvert finner Daniel hjemmesiden til Raballder på nettet: www.raballder.com. Der står det: "Raballder Håndballklubb: Norges skeiveste håndballklubb" i regnbuefarger. Daniel får sjokk:

Jeg slapp alt og bare stirra på den skjermen i flere minutter. Jeg var helt tom. Jeg forsto ingenting. [...] Jeg visste ikke om jeg skulle begynne å le eller gråte. Jeg var bare helt paff. Var det derfor de var så hyggelige, tenkte jeg (ler). Men det var en ganske heftig opplevelse... Siden så... det var vel et sjokk da - så da trente jeg ikke på to uker. Jeg måtte bare tenke litt.. Det var helt - helt sprøtt... hvordan skal det gå i garderoben og .. nei, det her kommer aldri til å gå, tenkte jeg lissom. Jeg bestemte meg for å si nei da. Slutte. Men etterpå så følte jeg litt sånn.. at jeg vil ikke være den som sier nei bare fordi de er homoseksuelle. Det er jo ikke egentlig min stil, for å si det sånn. Det skal jo ikke være noe.. - eller det er ikke noe problem uansett om de er homoseksuelle eller ikke. Også følte jeg at hvis jeg slutta på laget så skulle jeg jo skjemmes på en måte. For at jeg slutta på grunn av at de er homoseksuelle. Og da kjente jeg at det kunne jeg ikke gjøre.

Daniel hadde bestemt seg og dukket igjen opp på Raballders trening etter at han først hadde tatt en liten prat med klubblederen og sagt det som det var. På treningen ble han introdusert av lederen: "Dere må hilse på vår nye spiller. Noen av dere husker kanskje at han var innom her for en stund siden. Han heter Daniel, og han tror han er hetero...". Daniel rødmet kledelig, og alle flirte rått. Slik fikk Raballder en hetero på laget. Og det skulle vise seg at jeg fikk et spennende element i Daniel i forhold til noen spørsmål jeg hadde om Raballders potensial til å påvirke eller 'tilskeive' sine idrettslige omgivelser, både hva gjaldt 'heterokultur' og 'homokultur' i denne idrettskonteksten.

Nyheten om at Raballder hadde 'en hetero' på laget, var ingen hemmelighet. Daniel forteller om alle de rare reaksjonene han får fra omverdenen på at han spiller håndball i Raballder, og han forstår hvorfor de reagerer. Han sier om seg selv: "Den der snåle typen som er hetero som spiller på et homselag. Han må jo være helt teit i hue. Og det er jo rart ('merkelig'), 
jeg merker det jo sjøl at det er jo litt rart!" Jeg både overhørte og deltok i samtaler mellom motspillere, dommere, tilskuere etc., og reaksjonene jeg fikk se og høre når folk skjønte at det var en 'hetero' som spilte på Raballder var interessant. Det var tydelig at de ble overrasket og ikke forsto, samtidig med at de ble usikre i forhold til opplysningen (ansiktsutrykk/kroppsspråk generelt uttrykte vantro og latter, og hos noen ubekvemhet). Det ble kommentarer som: "Er de ikke homoer alle sammen altså?? Trodde det var et homolag jeg? Hvorfor vil han spille der'a?" Og fleiping dem i mellom: "Kanskje du skal melde overgang dit Einar? (latter). Hvor mange heteroer har de plass til da?" En 'hetero' på 'homolaget' kan berøre andre som lever heteroseksuelt på en måte som destabiliserer forestillingen om det 'rene homolaget', og som derfor gjør de absolutte grensene mellom 'hetero' og 'homo' mer utydelig. De som hittil har inntatt en bekvem kikkerposisjon overfor 'homolaget' som deltar i hovedkulturen i håndballhallen kan bli 'smittet' av Daniel; 'homolaget' kan nå også angå dem - når én 'hetero' spiller der, så kan også flere? Dette problematiserer fortåelsen av de rene representasjonene og tankemodellene om 'majoritet - minoritet', eller 'oss - og de andre'. Det er en tenkning basert på begreper om 'normalitet' kontra 'avvik' som beskriver befolkningen som delt inn i en statistisk størst majoritetsgruppe som befolker et demografisk og kulturelt sentrum, med ulike minoritetsgrupper spredd rundt i periferien som 'avvikere' i kontrast til det 'normale'/'vanlige'. I en slik modell framtrer kjente identitetskategorier som for eksempel homoseksuelle, innvandrere, funksjonshemmede etc. som grupper av avvikende minoriteter (Eng 2006a). Heteroseksuelle innslag i en entydig forstått 'homogruppe' beveger seg på kanten av det forståelige, og vil derfor kunne skape produktive brudd og slå sprekker, som produserer noe annet enn de bruddene som enkelt lar seg define- re inn $\mathrm{i}$ en annerledeshet som eksisterer $\mathrm{i}$ en getto på utsiden av 'hovedkulturen'. Daniel kan forstås som en hybrid figur som penetrerer grensen mellom majoritet ('hetero') og minoritet ('homo'), fordi han - forstått som hetero, er godt plassert i den store majoritetsgruppen, mens han som håndballspiller på Raballder plasserer seg som en aktør i homominoriteten.

Studier av heteronormativitet i det senmoderne har gitt en analytisk tilgang til å forstå en kulturs, eller samfunns displinering inn i normalitetsregimer på en annen måte enn det generelle fokuset på sexisme og homofobi. Kampen mot homofobi og sexisme har for eksempel i idretten gitt en politisk agenda som fremmer menneskerettigheter og likestilling på vegne av en gruppe i et samfunn (Sykes 1998:1), men de bryter ikke nødvendigvis ned forståelsen av noe som mer vanlig og normalt enn noe annet (og derfor har fortrinn som mest gjeldende) og kan derfor virke forsterkende på noen undertrykkende normalitetsregimer. I sitatet tidligere om Daniels inntreden i Raballder, fremstår han som en politisk korrekt person når han beskriver sin tvil om å skulle fortsette på Raballder. Han ville ikke være en som diskriminerte homoseksuelle; "jeg vil ikke være den som sier nei bare fordi de er homoseksuelle". Det er altså et 'drawback' at de er det, men han ønsker ikke å gjøre det til noe problem. 6 Daniel viser en respektfull avstandstagen til 'de homoseksuelle' som 'de andre' jmf. modellen majoritet - minoritet som konstituerende for en 'oss - og de andre' tenkning. Men når Daniel velger å bli en håndballspiller på Raballder, blir han selv en aktør med potensial til å bryte ned denne tankemodellen.

En måte å forstå begrepet heteronormativitet på er: “antagandet att alla är heterosexuella ock att det naturliga sättet att leva är heterosexuellt" (Rosenberg 2002: 100). Dette er en beskrivelse av heteroseksualiteten som norm, og som en tatt for gitt praksis. I tillegg blir heteronormativitet også forstått som en kompleks 
maktordning som disiplinerer til særskilte måter å leve det heteroseksuelle livet på: heteroseksualiteten må gjøres på den 'rette' måten (Sedgwick 1991, Mühleisen \& Røthing 2008, Kulick 2005, Eng 2006a) noe som også krever tilgang på den 'rette' formen for kapital, en tilgang som kan være avhengig av klasse, hudfarge, utseende, kjønn, alder m.m. (Nordin 2005: 26). I artikkelen Sex in Public (2002), presiserer derfor Lauren Berlant og Michael Warner at måter å gjøre heteroseksualitet på ikke alltid trenger å være heteronormative, og argumenterer videre for en forståelse av begrepet heteronormativitet som separat/forskjellig fra heteroseksualitet: "Heteronormativity is thus a concept distinct from heterosexuality" (Berlant \& Warner 2002: 309). Med dette får vi en definisjon av heteronormativitet som kan brukes til å analysere den naturaliserte heteroseksualiteten, eller det normative sentrum, på en slik måte at en også fanger de former eller uttrykk for heteroseksualitet som faller utenfor normen, og ikke bare de skeive minoritetsformene som åpenbart faller utenfor som kontraster til heteroseksualiteten. Sagt på en annen måte kan vi dele opp dette $\mathrm{i}$ to: 1. heteroseksualiteten som norm, og 2. normer for hvordan leve heteroseksuelt. Men begrepet 'heteroseksuelt' i punkt 2 virker forvirrende p.g.a. prefikset hetero, både når det gjelder 'homoseksuelle' som reproduserer normene for 'det gode/rette livet', 7 og 'hetero-seksuelle' som opponerer og bryter med disse normene i så måte. Jeg foreslår derfor at prefikset 'hetero' sløyfes i punkt 2 slik at det handler om: normer for hvordan leve seksuelt/kjønnet. Da åpner vi opp for å håndtere analytisk hele det normative feltet for hvordan leve det 'gode/riktige livet' uavhengig av å måtte kalle det for 'homo' og 'hetero', en normativitet som heller må beskrives innholdsmessig $\mathrm{i}$ forhold til det som analyseres.

\section{HOMONORMATIVITET}

Det er ikke bare normative krav om 'renhet' i 'majoriteten' som virker reproduserende på forståelsen av 'oss - og de andre', det er også normative krav om 'renhet' i forhold til tilhørighet i 'minoriteten' som er med og opprettholder denne tankemodellen. Som for heteronormativitet, er et av imperativene i homonormativiteten en entydig seksualitet; et 'rent' homoseksuelt begjær (Murphy, Ruiz \& Serlin 2008). Daniel som 'hetero' ble det stilt spørsmålstegn ved fra aller første møte mellom Daniel og Raballder (se sitat på side 22). Det er også relativt uvanlig med utøvere som lever heteroseksuelt på 'homoidrettslag', mye fordi det ofte er uttalte mål i 'homoidretten' om hovedsakelig å rekruttere og drive idrettsaktivitet for homofile og lesbiske (Elling \& de Knoop 2001) (se også formålsparagrafen på side 21). Jeg fikk flere ganger spørsmål fra utøverne på Raballder om jeg ikke kunne finne ut om "Daniel virkelig var 100 prosent hetero". Gjennom å delta som 'hetero' på et 'homolag', utfordrer Daniel konstruksjonen av et fellesskap basert på en homoseksuelt identitet. Daniel er også forundret over seg selv (se sitater på side 22). I motsetning til 'homoene' som enkelt kan plasseres utenfor det normale som 'de andre', blir Daniel en figur som skeiver til homoidrettslaget i seg selv. Og det interessante her er at Daniels medlemskap og aktive deltagelse $i$ 'de andres' klubb har potensial til å gjøre Raballder Håndballklubb mindre 'ren' (her i betydningen 'homo'), men samtidig mer 'queer/skeiv'.

Homonormativitet er et interessant begrep fordi det ikke kan oppnå like stor displinerende betydning som begrepet heteronormativitet. Berlant og Warner (2002: 309) sier følgende om dette: "Because homosexuality can never have the invisible, tacit, society-founding rightness that heterosexuality has, it would not be possible to speak of "homonormativity" in the same sense [as heteronormativity]". Det er altså det første kravet; 'heteroseksu- 
aliteten som norm' som gjør fenomenet heteronormativitet så mektig i en kultur som sees på som heteroseksuelt dominant. Homoseksualiteten som norm (forventningen om renhet - 'helt homo') er bare virksom for dem som lever tett på fenomenet homoseksualitet (oppfattes gjerne som en 'homo/lesbisk' minoritet) og kan ikke fă samme disiplinerende effekt på 'majoriteten' slik jeg forstår Berlant og Warner. Likevel mener jeg å se i studien min at brudd på homonormativiteten gir en tilskeivende effekt på forståelsen av 'oss - og de andre' både hos representanter for 'majoriteten' (mainstreamidretten) og for ' $m i-$ noriteten' ('homoidretten') i idrettskonteksten til Raballder. Daniels deltagelse forvirrer/provoserer både 'oss' (majoriteten) og 'de andre' (minoriteten). Hvordan var det mulig at Daniel ikke kunne se at Raballder var et 'homolag' før han fant nettsiden deres? Utøverne på Raballder kom stadig tilbake til dette spørsmålet, og det hadde sammenheng med den politiske agendaen om å være synlig som 'homoidrettslag'.

\section{SKRULLING $^{8}$ I GODE OG ONDE DAGER}

Raballder gjorde det ganske bra resultatmessig i 3dje divisjon, og det var ambisjoner i laget om å rykke videre opp i serien. På banen så jeg derfor et lag som absolutt var dyktige i håndball. Men jeg så også et lag som laget et 'annerledes' idrettshow på banen: Raballdergutta hadde jentenavn oppkalt etter stjernene på Norges suksesslandslag på damesida, og en av spillerne som hadde blondineparykk med lange tyrolerfletter skrek oppmuntrende: "Ja!!! Kom igjen'a jenter!!” Det var skrulling med feminine fakter, hyling og hvining, i kombinasjon med nydelige scoringer, kontringer med høyt tempo og en elegant veksling over til harde taklinger og forsvarspill. Spillerne på Raballder var opptatt av synlighet som et 'homoidrettslag', men på hvilken måte ville de være synlige? Sveinung forteller at da han kom inn i laget hadde Raballd- er et kamprop som lød: "Homo, homo, homo hei! Fitte e'kke no for meg!" Det var "for mye", synes Sveinung.

I løpet av den tida jeg fulgte Raballder skjedde det en endring som fikk synlige konsekvenser. I etterkant av et spillermøte fikk jeg høre at nå hadde de "vedtatt at de skulle slutte med skrullinga og satse på håndballen”. Skrulling - eller ikke, hadde vært et konflikttema i laget over ganske lang tid, og dette spillervedtaket førte til en periode hvor laget endret spillestil og noen utøvere forsvant fra trening og kamper. Dette viste hvor skarp balansegangen opplevdes angående bruken av virkemidler for å være synlige som noe annet enn 'hetero'. I denne tiden ble det nærmest helt slutt på det publikum nok oppfattet som 'homseshow' på håndballbanen. Innledningsvis $i$ artikkelen nevnte jeg hvordan bildet av Raballder illustrerer den doble iscensettelsen av kjønn. Raballder på banen vekslet også lett mellom disse to kjønnsutrykkene, og det var skrullingen som førte til mest bråk og uorden. Til forskjell fra det som er blitt mer vanlig i mainstream idrett av ulike underholdningsbidrag i pausene, hadde skrulling blitt iscenesatt i kampene som en del av spillestilen til Raballder. Internt skapte dette etter hvert slitasje fordi mange opplevde at showet sto $\mathrm{i}$ veien for sportslig fremgang og ambisjoner om opprykk i serien, samtidig som også mange ønsket seg noe annet enn bare fokus på idrettsprestasjon som de forbandt med 'vanlige' idrettslag de tidligere hadde deltatt i. "Jeg tenkte at det skulle være litt mer fyrverkeri”, sier Arnfinn om forventninger han hadde da han oppsøkte 'homoidrettslaget' Raballder. Og utad var det skrullingen som dro publikum, samtidig som at det kunne forsterke aggresjon, rått spill, hets og høy temperatur hos motstanderne og supporterne deres på tribunen: "De [motstanderne] syns vel kanskje det [skrullingen] ble litt i meste laget, men publikum elska det jo! De syns jo det var så gøy. [...] Tenk, homser spiller håndball! Går det an!” (Arnfinn) 
Skrulling kan forstås som en bevisst strategi i kampen mot homonegativisme og homohets. Kjønnsinversjon (bruk av hunkjønnsord med mannlig referent) i språkbruk og i iscenesettelse forøvrig, kan brukes som en form for motmakt, eller "mothegemonisk diskurs" (Johnsen 2001: 376). Noen av utøverne på Raballder snakker om å “spille på fordommer", for dermed - slik jeg tolker det - å framprovosere en mulig grense for aksept for annerledeshet $\mathrm{i}$ håndballhallen. Kim sier: "Men vi er mye friere (enn motstanderne) i forhold til seksualitet, og (vi) spiller på fordommer og sånne ting. Og fordommene er jo at man er feminin, og da spiller man ofte på det". Sveinung bruker gjennom skrullinga humor og selvironi som en motsetning til å bli bitter og såret når homohetsen treffer: "Jeg skruller masse. Jeg fjåser og fjaser, men det er jo mer for å kunne si at liksom ja, haha, se på meg; jeg er... Altså blir litt sånn... selvironisk, leke litt med fordommer - uten at det liksom blir sånn bittert at; 'å fy faen altså de kalte meg for homo altså!', hvis du skjønner".

Hvorfor er så skrulling provoserende for motstanderlagene og deres supportere? Jeg vil hevde at det først og fremst handler om at utøverne på Raballder gjennom å spille håndball under merkelappen 'homoidrettslag' blir forstått som 'de andre' - homsene. Skrullingen preget håndballkampen i den grad at motstanderlaget ufrivillig ble en del av showet. "De blir utsatt for homofile", sier Mons. Motstanderne skriker "ta dere sammen, jævla kjærringer”. Mons sier videre: "Homofile er litt sånn mindreverdige menn. [...] det er verre å tape for en gjeng med skruller, enn å tape for et lag med helt vanlige håndballspillere som viser seg å være homo". Det er heller ikke ukjent for utøverne på Raballder som også har spilt håndball utenom homoidrettslag, at skrulling forekommer i de andre lagene: "Alle lag har ei fjåse", sier Sveinung, og Mons forteller om guttas dragshow med G-string truser i idrettsmiljøet han spilte $\mathrm{i}$ før han begynte på Raballder. Femininitet som show gjort av menn trenger ikke true en tradisjonell mannlighet, når det gjøres i en heteroseksuell kodeks (Pronger 1990, Owen 2006).

'Homolaget' Raballder sitt show på håndballarenaen kan derfor være overskridende i forhold til å 'smitte' en 'seriøs' idrettskonteks både gjennom å bringe inn seksualitet som et uønsket element, og gjennom å skrulle fram et show som fører håndballidretten over i homounderholdningssjangeren. I løpet av feltarbeidet mitt kom jeg i kontakt med den regionale Håndballkretsen. De kunne fortelle meg at de hadde hatt møter sentralt i forkant av sesongen, for å legge opp en slagplan i tilfelle det ble ubehagligheter i forhold til ryktet til håndballidretten generelt. ${ }^{9}$ Dette bekrefter inntrykket av at det er mulig at fenomenet 'homoidrett' kan gjøre noe med fortellingene om norsk idrett, og at det kanskje sier noe om alvoret i det Raballder representerer.

Jeg har i denne artikkelen argumentert for at Raballder fremstår med et potensial til å "fuck up the mainstream", men det er tydelig at denne prosessen er krevende og at den skaper bråk både eksternt og internt. Kim og de andre sin skrulling tydeliggjør at homolaget ikke nøyer seg med en fredelig sameksistens basert på aksept av 'homolaget' på heteromaskulinitetens premisser. Samtidig sluttet Raballderlaget med skrulling fordi det ble for mye støy. Den forvirringen Daniel som en hybrid figur skapte angående et 'homolag' derimot, så ut til å fungere konfliktløst og tilskeivende i forhold til normative forventninger i idettskonteksten. Raballder som idrettslag klarer å skape noe rundt seg vedrørende sin formålsparagraf om synlighet av "idrett og homofili".

Jeg vil hevde at studier av politiske strategier og spørsmål om potensiale for queering av en heteronormativ kontekst i feltet 'homoidrett' er både interessant og viktig. Men som en avsluttende kommentar vil jeg peke på en utfordring i forhold til 
videre forsking på dette; en politisk strategi som går ut på å eksponere det skeive (queer) i en kontekst som forstås som 'straight' og 'normal' (Roseneil 2000) er avhengig av å kunne fremvise brudd på det forventede. Hva som er det forventede, og potesielle brudd på disse vil variere over tid. Etter en stund blir kanskje det 'skeive nye', assimilert og plassert i det 'normale', og stadig nye overraskelser og vendinger må til. Kanskje dette kun ender et sted der alt blir queer, og dermed ingenting queer?

\section{Noter}

1. Det som etterhvert ble beskrevet som 'heteronormativity' (Berlant \& Warner 2000), og som er så mye i bruk som et analytisk begrep både i forskning og politikken. Mer om dette begrepet kommer videre i artikkelen.

2. Raballder har i tillegg også andrelaget i 5. divisjon herrer, samt et mer nyetablert damelag i 6 . divisjon. Jeg bruker her begrepet 'vanlig' seriespill i motsetning til bedriftsserien, som er den serien de fleste 'homoidrettslagene' i Norge deltar i. Internasjonalt er disse lagene oftest aktive i egne serier/turneringer for homoidrettslag (Jarvis 2006: 64-65), et felt som er sterkt voksende både nasjonalt og internasjonalt med 'World Outgames' i København i 2009 som et godt eksempel.

3. Gay Games, World Outgames, og Eurogames er eksempler på internasjonale idrettsarrangementer initiert som et 'homoalternativ' til mainstream idrettens store internasjonale turneringer som Olympic Games og World Games. Gay Games var først ute, med Tom Waddell fra USA i spissen for det de ville kalle Gay Olympics i 1980. U.S. Olympic Committee (USOC) gikk rettens vei for å stoppe dette initiativet, og vant saken i amerikansk høyesterett. Men med navnet Gay Games kunne det første arrangementet finne sted i San Francisco i 1982 med ca 1.300 deltagere (Young 1995: 25). Siden er det blitt holdt hvert fjerde år, senest $\mathrm{i}$ 2006 med 12.000 deltagere.

4. Jeg fikk rik tilgang til innsyn i feltet gjennom at jeg fikk være klubbens trener og lagleder (herrenes førstelag) i denne sesongen, noe som innebar at jeg fulgte laget også på spillermøter, i sosiale lag, på taktikkmøter/debriefing i garderoben, og på reise til og fra kamper. Som feltarbeider var jeg derfor en observerende deltager, snarere enn en deltagende observator (Bernard 1995: 138). Alle per- sonnavn som brukes på spillere, trenere, dommere m.m. i artikkelen er oppdiktet. Det er likevel umulig å ivareta fullstendig anonymitet i denne undersøkelsen, da homoidrettsmiljøet i Norge er liten. Det er for eksempel bare en håndballklubb som deltar i vanlig seriespill, de andre lagene deltar i bedriftsidrett. Jeg har derfor valgt å ikke finne et pseudonym for navnet på idrettsklubben jeg har gjort feltarbeid i.

5. I Norge er begrepet queer og queering blitt oversatt med 'skeiv' og tilskeiving. I artikkelen bruker jeg begge.

6. Garderoben er rett nok noe han gruer seg for. Det understøtter forskning som viser at det er først når ordet 'homoseksualitet' aktiveres at samvær og aktiviteter i potensielt homoerotiske rom blir truende (Eng 2003, Pronger 1990, Messner \& Sabo 1994).

7. Felles ekteskapslov (Norge i 2008), gjør det for eksempel enda tydeligere at homoseksuelle par like mye som heteroseksuelle kan velge å leve et liv som reproduserer og styrker vår kulturs normative forestillinger om hva som utgjør 'det rette/gode liv'.

8. 'Skrulling' er et norsk ord som brukes på homofile menns lange tradisjon for å bruke kjønnsinversjon i språk og handling (Johnsen 2001) på en måte som kan assosieres med feminine menn eller 'queens'.

9. Raballder hadde vinteren 2006 en egen TVserie på TV2, noe som gjorde Håndballkretsen ekstra oppmerksom på muligheter for at håndballidretten skulle få mye oppmerksomhet i det offentlige på en måte de følte "var utenfor kontroll".

\section{LITTERATUR}

- Anderson, Eric (2005): In the Game: Gay Athletes and the Cult of Masculinity. State University of New York Press, NY.

- Berlant, Lauren \& Warner, Michael (2002) Sex in Public, i Michael Warner (ed.) Publics and Counterpublics. Chicago University Press, Chicago. - Bernard, H. Russell (1995): Research Methods in Anthropology: Qualitative and Quantitative Approaches. AltaMira Press, Walnut Creek, CA.

- Bridel, William \& Rail, Geneviève (2007): Sport, Sexuality, and the Production of (Resistant) Bodies: De-/Re-Constructing the Meanings of Gay Male Marathon Corporeality, i Sociology of Sport Journal, $2007 / 24$.

- Caudwell, Jayne (ed.) (2006): Sport, Sexuality and Queer/Theory. Routledge, London. 
· Elling, Agnes \& Claringbould, Inge (2005):

Mechanisms of Inclusion and Exclusion in the Dutch Sports landscape: Who Can and Wants to Belong? i Sociology of Sport Journal, 2005/22.

- Elling, Agnes \& De Knop, Paul (2001): The Social Integrative Meaning of Sport: A Critical and Comparative Analysis of Policy and Practise in the Netherlands, i Sociology of Sport Journal, 2001/18. . Eng, Heidi (2003): Sporting Sexuality: Doing Sex and Sexuality in a Norwegian Context. Dissertation. Norwegian University College, Oslo.

- Eng, Heidi (2006a): Homo- og queerforskning, i Jørgen Lorentzen \& Wencke Mühleisen (red.) Kjønnsforskning: En grunnbok. Universitetsforlaget, Oslo.

. Eng, Heidi (2006b): "We are moving up like a hard-on!": Doing sex/uality in sport, i NORA:

Nordic Journal of Women's Studies, 2006/14.

. Eng, Heidi (2008): Doing Sexuality in Sport, i Journal of Homosexuality, 2008/1-2.

- Johnsen, Ole (2001): Søstre, venninner og luddere: Kjønnsinversjon i homsers språkbruk, i Marianne Brantsæter; Turid Eikvam, Reidar Kjær \& Knut Olav Åmås (red): Norsk homoforskning. Universitetsforlaget, Oslo.

- Kulick, Don (2005) (red.): Queersverige. Bokförlaget Natur och Kultur, Stockholm.

- Kulick, Don (1996): Queer Theory: Vad är det och vad ër det bra för?, i Lambda Nordica, 1996/3-4.

- Larsson, Håkan (2005): Queer idrott, i Don Kulick (red): Queersverige. Bokförlaget Natur och Kultur, Stockholm.

- Messner, Michael \& Sabo, Don (1994): Sex, Violence and Power in Sports: Rethinking Masculinity. Beacon Press, Boston.

- Murphy, Kevin, P.; Ruiz, Jason \& Serlin, David (2008) Editors' Introduction, i Radical History Review, 2008/100.

· Mühleisen, Wencke \& Røthing, Åse (2008) (red.) Norske seksualiteter. Cappelen, Oslo.

- Nordin, Lissa (2005): När man inte vil vara själv, i Don Kulick (red): Queersverige. Bokförlaget Natur och Kultur, Stockholm.

- Owen, Gareth (2006): Catching crabs: bodies, emotions and gay identities in mainstream competitive rowing, i Jayne Caudwell (ed): Sport, Sexuality and Queer/Theory. Routledge, London.

- Pronger, Brian (1990): The Arena of Masculinity: Sports, Homosexuality, and the Meaning of Sex. GMP Publishers Ltd., London.

- Price, Michael \& Parker, Andrew (2003): Sport, Sexuality, and the Gender Order: Amateur Rugby Union, Gay men, and Social Exclusion, i Sociology of Sport Journal, 2003/20.
- Raballder (2009):

http://idrett.speaker.no/Downloads/469872/do cs/Statutter_for_Raballder_Håndball.doc

- Rosenberg, Tiina. (2002): Queerfeministisk

Agenda. Atlas, Stockholm.

- Roseneil, Sasha (2000) Common Women, Uncommon Practices: The Queer Feminisms of Greenham. Cassell/ Continuum, London.

- Roseneil, Sasha (2003): Queer Frameworks and Queer Tendencies: Towards an Understanding of Postmodern Transformations of Sexuality', i Kvinder, Kon \& Forskning, 2003/1.

- Sedgwick, Eve, K. (1991): Epistemology of the Closet. Harvester Wheatsheaf, New York.

- Smyth, Cherry (1992): Lesbians Talk Queer Notions. Scarlet Press, London.

- Sykes, Heather (1998): Turning the Closets Inside/Out: Towards a Queer-Feminist Theory in Women's Physical Education, i Sociology of Sport Journal, 1998/15.

- Young, Perry Deane (1995): Lesbians and Gays in Sports. Chelsea House Publishers, New York.

- Warner, Michael (1999): The Trouble with Normal, The Free Press, New York

\section{SUMMARY}

A straight guy on the team.

'Raballder' is a Norwegian gay handball team competing in the mainstream national handball league. As a team they have a political consciousness towards contributing in making a difference being the only gay team in a 'straight' handball environment in Norway. The article discuss the team's potentiality to queer up the handball arena, looking at two elements in particular that emerged during the competition season 2006/2007: 1) a straight guy enters as a player on the gay team, and becomes a figure in queering the mainstream handball context, 2) An internal conflict emerges in the team concerning the players enacting as heteronormative macho sportsmen versus as effeminate gay 'queens' on the handball field. The latter is recognizable as gay culture which seems in this Norwegian sports context to have a deconstructive potential on male heteronormative, competitive sport.

Heidi Eng, førsteamanuensis

Diakonhjemmet Høgskole 